\title{
REFLEXÕES SOBRE UM MODELO DE ENSINO DA BÍBLIA QUE FORME PESSOAS SOLIDÁRIAS
}

Adolfo Semo Suárez ${ }^{1}$ adolfo.suarez@unasp.edu.br Centro Universitario Adventista de São Paulo, UNASP

\section{Resumo}

Este artigo aborda de forma significativa a importância e o impacto da aplicação da filosofia da educação cristã na realização do trabalho educativo. Neste trabalho destaca-se a educação que a igreja, através da Escola Sabatina e outros meios de comunicação, sempre manteve e que actualmente é confirmada por investigações acadêmicas. A riqueza desta pesquisa esta baseada no modelo onde o autor fornece o "saber" e o "fazer" achando seu ponto médio, sem tirar tempo e espaço um do outro. ¿Como saber deste equilíbrio? Através do ensino de valores bíblicos que incluem ambas das partes essenciais de um processo de aprendizagem: o saber e o fazer. Finalmente, o autor sugere que esta iniciativa educacional deve ser adoptadas por todas as escolas adventistas.

Palabras claves: Educação, Biblia, modelos educacionais, valores.

\footnotetext{
${ }^{1}$ Mestre e Doutor em Ciências da Religião. Pós-Doutor em Teologia. Coordenador da Faculdade de Teologia do UNASP, campus Engenheiro Coelho. Professor de Teologia, na Graduação e Pós-Graduação. Professor do Master in Leadership, programa oferecido pela Andrews University no UNASP, campus Engenheiro Coelho.
} 


\section{REFLECTIONS ON BIBLICAL TEACHING MODEL TO EDUCATE SOLIDARITY PEOPLE}

\section{Abstract}

This paper addresses with great breadth the importance and impact of the application of the philosophy of Christian education when undertaking educational work. This work highlights the education that the church, through the Sabbath School and other forms, has always maintained and is now confirmed by academic studies. The richness of this research is in the model that the author provides, where "knowing" and "doing" find its midpoint without trim time and space from each other. How does this balance? Through biblical values teachings, which include both essential parts of a learning process: knowing and doing. Finally the author suggests that this educational initiative should be adopted by all Adventist educational institutions.

Keywords: Education, Bible, educational models, values. 


\section{Introdução}

É sabido que educar não é apenas transmitir conhecimentos. To- mando como parâmetro os quatro pilares da educação assumidos oficialmente pela Unesco a partir de 1996, diríamos que educar é desen-

\begin{tabular}{|ll|}
\hline Aprender a aprender & $\rightarrow$ priorizar as experiências de aprendizagem \\
Aprender a fazer & $\rightarrow$ ênfase nas competências e habilidades \\
Aprender a viver juntos & $\rightarrow$ juntar competência e solidariedade \\
Aprender a ser & $\rightarrow$ realizar-se como individuo e ser social
\end{tabular}

volver o aluno em quatro aspectos complementares: ${ }^{2}$

Normalmente, as escolas se preocupam em passar um conteúdo (saber) e implementar alguma atividade (fazer), negligenciando, entre outras coisas, o desenvolvimento das competências necessárias para obter um espaço no mercado de trabalho, assim como o cultivo e prática da solidariedade, tão necessária neste mundo por vezes desumano e individualista.

Mas, será possível ensinar solidariedade num espaço chamado "sala de aula"? Rubem Alves acha que não. Ele diz:

${ }^{2}$ Hugo Asmann y Jung Mo Sung, Competência e sensibilidade solidária: educar para a esperança, (Rio de Janeiro: Editora Vozes, 2000), 211.
Ensinar primavera às areias e gelos é coisa difícil. Gelos e areias nada sabem sobre primaveras... Pois eu desejaria saber ensinar a solidariedade a quem nada sabe sobre ela. $\mathrm{O}$ mundo seria melhor. Mas como ensiná-la?

Será possível ensinar a beleza de uma sonata de Mozart a um surdo? Como? - se ele não ouve. E poderei ensinar a beleza das telas de Monet a um cego? De que pedagogia irei me valer para comunicar cores e formas a quem não vê? Há coisas que não podem ser ensinadas. Há coisas que estão além das palavras. Os cientistas, filósofos e professores são aqueles que se dedicam a ensinar as coisas que podem ser ensinadas. Coisas que podem ser ensinadas são aquelas que podem ser ditas. Sobre a solidariedade muitas coisas podem ser ditas. Por exemplo: 
acho possível desenvolver uma psicologia da solidariedade. Acho também possível desenvolver uma sociologia da solidariedade. E, filosoficamente, uma ética da solidariedade... Mas os saberes científicos e filosóficos da solidariedade não ensinam a solidariedade, da mesma forma como a crítica da música e da pintura não ensina às pessoas a beleza da música e da pintura...

A solidariedade não é uma entidade do mundo de fora, ao lado de estrelas, pedras, mercadorias, dinheiro, contratos. Se ela fosse uma entidade do mundo de fora ela poderia ser ensinada. A solidariedade é uma entidade do mundo interior. Solidariedade nem se ensina, nem se ordena, nem se produz. A solidariedade, semente, tem de nascer... ${ }^{3}$

Obviamente não é suficiente ficar no campo da poesia, e contentar-se com a impossibilidade filosófica de se ensinar solidariedade, conforme argumenta Rubem Alves. Entretanto, o questionamento é válido: Ensinar solidariedade?

${ }^{3}$ Rubem Alves, http://www.direito. ufjf.br/rede/temas/ant_temas_julho01. html., (Acesso em 09 outubro de 2003).
Como? É isso possível a partir do ensino da Bíblia?

O objetivo deste artigo é apresentar uma alternativa para se trabalhar a solidariedade mediante o ensino da Bíblia, seja na Escola ou na Universidade. Esta alternativa é no campo da metodologia, pois acredito que, pela sua própria natureza, o ensino da Bíblia requer uma abordagem diferenciada.

Este trabalho está estruturado em duas seções; a primeira discorre sobre a criatividade como elemento fundamental numa prática educativa que promova a solidariedade, enquanto que a segunda seção apresenta uma abordagem ou estrutura de ensino da Bíblia que valorize e promova aprendizagem e formação de vida solidárias.

É importante esclarecer que esta abordagem de ensino da Bíblia se enquadra numa perspectiva de Filosofia de Educação Cristã, especificamente numa prática educacional das instituições educacionais Adventistas, mantidas pela Igreja Adventista do Sétimo Dia. 


\section{A criatividade no ensino da Bíblia}

Hoje em dia se procura pessoas com criatividade e iniciativa, capazes de serem flexíveis em termos de trabalho. Pessoas que não possuem uma postura de iniciativa e criatividade têm dificuldade em conseguir empregos antes vistos como simples. Mas não é só isso. No âmbito da solidariedade, não é possível uma pessoa ser solidária com alguém que necessita de ajuda sem ser capaz de iniciativa e criatividade. Por que? Porque ações concretas de solidariedade envolvem iniciativa e criatividade das pessoas, a fim de encontrar a oportunidade apropriada e os meios necessários para estender a mão a quem precisa ou para simplesmente fazer o outro se sentir gente. ${ }^{4}$

${ }^{4}$ No livro do Jung Mo Sung, Conhecimento e solidariedade (São Paulo: Editora Salesiana, 2002), ele defende a postura de uma maneira muito clara, argumentando que o mercado de trabalho requer uma escola diferenciada, em sintonia com as demandas de nossa época, pois o que se ensinava há uma década não é mais útil para o momento que vivemos.
Sendo que a iniciativa e criatividade são elementos cada vez mais exigidos pelo mercado de trabalho, pode-se concluir que a escola e a universidade devem educar para a iniciativa e criatividade.

\section{Crise de criatividade no ensino da bíblia}

Qual é maior dificuldade que os professores de Bíblia enfrentam em sala de aula? As respostas podem ser as mais diversas, mas é possível que num aspecto todos os profissionais dessa área concordem: Talvez a maior dificuldade não seja encarar uma turma indisciplinada, ou explicar um conteúdo difícil; uma das maiores dificuldades do professor de Bíblia é apresentar aulas criativas, das quais os alunos gostem, e nas quais aprendam, resultando num bom ambiente de aprendizado; aulas que promovam envolvimento e dinamismo.

O mundo está cheio de coisas criativas: brinquedos, revistas, músicas, livros, softwares, filmes etc. Empresários, atores e apresentadores de TV são criativos. Todavia, dia-a-dia convivemos com uma dura realidade: Há muitos professores de Bíblia que geralmente come- 
çam sua aula mais ou menos assim: "Atenção pessoal. Vamos abrir o livro na página... A lição de hoje se chama.... É uma lição muito importante..."

Pelas palavras de abertura da aula, pode-se concluir que tais professores não se preocupam em usar a criatividade. Não são professores criativos. Suas aulas são previsíveis, cansativas e monótonas. São cheias de informação, mas, pela maneira como as informações são apresentadas, tem pouco ou nenhum benefício. Vivem no colorido e criativo século XXI, mas insistem em praticar a arte de ensino apenas em preto e branco. Seus alunos têm computador, internet, vídeo-game, TV, som, mas eles preferem ensinar como antigamente: apenas giz e "quadro negro", num ensino centralizado no professor.

\section{Pressupostos de uma aula criativa de Bíblia}

\section{$O$ aluno deve ser o centro do processo}

Bruce Wilkinson ${ }^{5}$ nos lembra

${ }^{5}$ Bruce Wilkinson, As 7 leis do aprendizado (Madrid: Editora Betânia, 2010), 23- 24. que os três principais elementos de todo ensino são o professor, o assunto e o aluno. As aulas que normalmente focalizam a atenção no professor ou no assunto produzem estudantes passivos, cuja função é apenas olhar, ouvir e escrever. Mas quando a atenção é deslocada para o aluno - colocando o professor e assunto à disposição deste -, o resultado é alunos comprometidos, envolvidos e interessados no aprendizado. ${ }^{6}$

\section{$\mathrm{O}$ professor precisa promover a fuga da rotina e acomodação}

Em vez de começar a aula com o tradicional vamos abrir o livro na página..., o professor que pratica um ensino bíblico criativo prefere:

- Contar uma história para captar a atenção da classe;

- Ler uma frase de impacto para fazer os estudantes pensarem a respeito do tema a ser apresentado;

- Mostrar uma figura relacio-

${ }^{6}$ Ibíd., 40-61 o autor trata amplamente do cuidado que o professor deve ter com os três elementos do aprendizado. 
nada com o assunto a aula, a fim de provocar comentários sobre as implicações de tema em questão;

- Apresentar um vídeo como introdução do assunto em pauta;

- Partir do conhecido para o desconhecido, do geral para o particular;

- Ouvir a opinião do aluno a respeito do tema mais discutido no momento nos meios de comunicação, etc.

\section{A atenção do aluno deve ser con- quistada através de um objeto, material etc.}

Por exemplo:

- Para falar sobre Criação e Evolução, o professor ganha a atenção dos alunos mostrando fósseis;

- Para falar sobre o material em que a Bíblia foi escrita, o professor mostra um papiro;

- Para falar sobre o Dilúvio, o professor apresenta uma miniatura da Arca de Noé;

- Para falar sobre o Ministério de Cristo como Sumo Sacerdote, o professor mostra uma réplica do Santuário Terrestre.

\section{A aula deve despertar a motiva- ção para o aprendizado}

Howard Hendricks argumenta que "o ensino será mais eficiente quando o aluno se encontrar adequadamente motivado". ${ }^{7}$ Hendricks destaca o fato de que a motivação está diretamente ligada com a curiosidade (a curiosidade permite ganhar a atenção inicial do aluno), utilidade (é mais fácil aprender quando o que se aprende é útil e aplicável à vida prática), atendimento de necessidades (se o que o professor está ensinando é necessário para o aluno, este acaba aprendendo com maior facilidade) e desafios (quanto mais desafiador e intrigante o ensino, mais motivação há para aprender). ${ }^{8}$

${ }^{7}$ Howard Hendricks, Ensinando para transformar vidas (Miami: Editorial Unilit, 2003), 107.

${ }^{8}$ Ibid., 106. 


\section{O professor precisa primar pelo entusiasmo}

Antigamente, entusiasmo significava a exaltação ou arrebatamento daqueles que estavam sob inspiração divina.9 A aula criativa de Bíblia, portanto, é o resultado de um professor com dedicação ardente em tudo o que faz, falando e agindo com veemência, vigor e paixão. ${ }^{10}$

O professor deve despertar nos alunos a curiosidade pela aprendizagem: eu quero saber isso aí!

Nas palavras de Marcos Tuler, “o ensino dinâmico e produtivo é aquele que provoca nos alunos uma sensação de intensa vontade de aprender". 11 O ensino criativo da Bíblia produz estudantes ansiosos por descobertas e um novo horizonte no âmbito do conhecimento e da vida cristã prática.

${ }^{9}$ Marcos Tuler, Manual do Professor de Escola Dominical: Didática aplicada á realidade do ensino cristão (Rio de Janeiro: Casa Publicadora das Assembleias de Deus, 2011), 115.

${ }^{10}$ Idíd.

${ }^{11}$ Ibíd., 105.

\section{O professor deve tornar o apren- dizado divertido}

Para muitos juvenis, adolescentes e jovens, a ideia de se divertir está normalmente relacionada a algo ilegal ou até prejudicial. A aula de Bíblia deve propiciar-lhes um ambiente no qual aprendam brincando, rindo e divertindo-se, ${ }^{12}$ sem necessariamente perder o respeito pelo que é sagrado. Um ambiente descontraído atrai as pessoas à fé cristã. ${ }^{13}$

\section{$\mathrm{O}$ professor precisa respeitar o ritmo e características de apren- dizagem de cada aluno}

Cada estudante aprende de maneira diferenciada. Se o professor souber lidar com essas diferenças, adequando seu ensino considerando essas particularidades, terá estudantes sempre atentos e participativos.

Marlene D. LeFever ${ }^{14}$ afirma

${ }^{12}$ Ray Johnston, Socorro! Meus alunos sumiram! 50 dicas práticas para transformar sua escola dominical (Madrid: Editorial Betânia, 1998), 34, 35.

${ }^{13}$ Ibid., 35.

${ }^{14}$ Marlene Lefever, Estilos de Aprendizagem: Como alcançar cada um que 
que há quatro tipos de aprendizes. Os aprendizes interativos são pessoas sensíveis que se envolvem com outras e aprendem melhor em contextos que possibilitam o desenvolvimento de relacionamentos interpessoais. Também aprendem ouvindo e compartilhando ideias. $\mathrm{O}$ aprendiz interativo gosta de ler a Bíblia para ter respostas para os por quês; ele vê na aula de Bíblia a grande possibilidade para obter respostas às suas inquietações existenciais.

Por outro lado, os aprendizes analíticos adquirem conhecimento observando e ouvindo; ficam sentados avaliando com cuidado a informação que é apresentada. Querem, primeiro, obter todos os dados para, depois, tomar uma decisão. $\mathrm{O}$ aprendiz analítico gosta de ler a Bíblia para tirar conceitos e princípios; ele vê a aula de Bíblia como oportunidade para aprender normas para sua vida pessoal.

Outro grupo de aprendizes é chamado de pragmáticos. Os aprendizes pragmáticos gostam de

Deus the confiou para ensinar (Rio de Janeiro: Casa Publicadora da Assembleia de Deus, 2002),17-9. brincar com ideias para ver se elas são racionais e funcionais. Testam a teoria no mundo real para aplicar o que aprenderam; amam ver o trabalho realizado. $O$ aprendiz pragmático lê a Bíblia para saber como desenvolver um cristianismo de ação, prático. Vê a aula de Bíblia como o espaço para executar projetos comunitários e religiosos.

Finalmente, os aprendizes dinâmicos gostam da ação como parte do processo de aprendizagem. Mais do que seguir cartilhas prontas, destacam-se por seguir a intuição a fim de encontrar novas direções e possibilidades. $\mathrm{O}$ aprendiz dinâmico lê a Bíblia para poder expandir sua visão e ação de cristianismo. Vê a aula de Bíblia como o espaço certo para aprender a viver o cristianismo ideal.

Os diferentes tipos de aprendizes explicam por que nem todos se entusiasmam com as atividades propostas em sala de aula, por mais elaboradas que elas sejam. A aula criativa, então, tem o desafio de atingir cada aluno, respeitando e considerando seu estilo de aprendizagem. 
A aula deve provocar não um impacto passageiro, mas uma transformação duradoura do coração

Divertir os alunos, transmitir informação e controlar a disciplina são tarefas relativamente fáceis de executar. Mas o ensino da Bíblia leva em conta que ensinar tem como resultado final a transformação total de uma personalidade, operada pela graça e poder de Deus. ${ }^{15}$

\section{Uma Ponte com a Solidariedade}

De que maneira as ideias apresentadas acima, a respeito dos pressupostos de uma aula criativa da Bíblia, estão ligadas ao tema da solidariedade? Creio que as reflexões a seguir podem esclarecer essa questão:

- $\mathrm{O}$ aluno deve ser o centro do processo: a partir do momento que o professor focaliza a atenção no aluno, tornando-o o centro do processo ensino-aprendizagem, o aluno se torna sujeito ativo, participativo. Dessa maneira, ele pode

${ }^{15}$ Hendricks, 91. participar e envolver-se em tudo o que acontece em sala de aula, desde a escolha de temas para debate, até o planejamento e execução de um projeto comunitário.

- O professor precisa promover a fuga da rotina e acomodação: isto possibilita o pensar em maneiras criativas de ajudar o próximo, por exemplo. Afinal, ser solidário não é apenas dar esmolas ou um prato de comida.

- A atenção do aluno deve ser conquistada através de um objeto, material etc.; novamente, o elemento chave aqui é a criatividade, que possibilita a invenção de novas maneiras de ajudar o outro.

- A aula deve despertar a motivação para o aprendizado: aqui se pode pensar numa solidariedade inicialmente mecânica, mas que caminha rumo a uma prá- 
tica cada vez mais madura, motivada pela interdependência, imposição ética ou pelo imprinting cultural. ${ }^{16}$

- O professor precisa primar pelo entusiasmo: alunos são facilmente motivados para a execução de qualquer projeto se são liderados por um professor entusiasmado, que esbanja disposição e ânimo.

- $\mathrm{O}$ professor deve despertar nos alunos a curiosidade pela aprendizagem: mais uma vez, o elemento chave aqui é a criatividade, que permite sugerir novas maneiras de ajudar o outro.

- O professor deve tornar o aprendizado divertido: a solidariedade deve ser encarada como uma atividade agradável, pois estudantes, especialmente juvenis e adolescentes, são facilmente fisgados por práticas entusiastas e divertidas.

- $O$ professor precisa respei- tar o ritmo e as características de cada aluno: cada aluno pode participar de maneira diferenciada, considerando que cada um tem seu jeito de ser.

- A aula não deve provocar um impacto passageiro, mas uma transformação duradoura do coração: a solidariedade não deve estar restrita a momentos de solidariedade; ela deve ser uma maneira de viver e pensar.

\section{Uma abordagem apro- priada para o ensino da Bíblia}

Para ser criativo e dinâmico, motivando no aluno a interdependência e espírito solidário, a estrutura da aula de uma aula de Bíblia deve seguir um ritmo diferente daquele normalmente usado nas outras disciplinas. A dinâmica deve ser completamente diferente, pelas seguintes razões:

\footnotetext{
${ }^{16}$ Asmann e Mo Sung, 200-1.
} 
- O professor de Bíblia não deve usar o argumento de "eu vou me cobrar na prova", ou "isto cai na prova", pois atribuiria à matéria um sentido apenas acadêmico. Portanto, a aula em si deve se constituir em atrativo para captar e manter a atenção do aluno.

- Há uma tendência natural de preconceito toda vez que o assunto envolve religiosidade ou assuntos morais.

- Numa sala de aula há diversidade religiosa; portanto, o ritmo da aula deve respeitar os diversos credos religiosos.

Por isso, pensando num ensino-aprendizagem criativos, no qual o aluno de fato aprenda e desenvolva um forte senso de interdependência, creio ser apropriada a abordagem de Lawrence Richards. ${ }^{17}$ Ele

\footnotetext{
${ }^{17}$ Lawrence Richards e Gary J. Bredfeldt, Creative Bible Teaching (Chicago: Moody Press, 1998), 75. As cinco palavras sugeridas por Richards são, respectivamente, Memorização, Reconhecimento,
}

sugere uma metodologia diferenciada para aulas de Bíblia, que consiste em cinco passos extraordinários, apresentados a continuação:
Verbalização, Relacionamento e Reação ou Resposta. Aqui elas foram adaptadas para uma maior clareza, e o conceito que cada palavra encerra foi expandido dentro de um contexto de ensino dinâmico e participativo que, por filosofia, deveria caracterizar as aulas de ER nas Escolas Adventistas. 


\section{Os Cinco Passos do Ensino Criativo da Bíblia}

\begin{tabular}{|c|c|c|c|c|}
\hline & & & & $\begin{array}{l}\quad \text { DECISÃO } \\
\text { O professor leva o } \\
\text { aluno a ter uma } \\
\text { postura pessoal em } \\
\text { relação ao que foi } \\
\text { estudado. } \\
\text { O estudante aplica a } \\
\text { verdade bíblica em } \\
\text { sua vida diária. }\end{array}$ \\
\hline & & & $\begin{array}{l}\quad \text { REFLEXÃO } \\
\text { O professor faz o } \\
\text { aluno pensar a res- } \\
\text { peito das implicações } \\
\text { gerais do assunto em } \\
\text { questão. O estudante } \\
\text { relaciona o conteúdo } \\
\text { com o mundo ao } \\
\text { redor. }\end{array}$ & 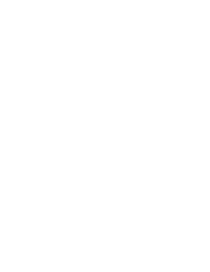 \\
\hline & & \begin{tabular}{l}
\multicolumn{1}{c}{ EXPRESSÃO } \\
O professor sugere \\
atividades interessan- \\
tes e significativas. O \\
estudante realiza as \\
atividades sugeridas.
\end{tabular} & & \\
\hline & $\begin{array}{l}\text { RECONHECIMEN- } \\
\text { TO } \\
\text { O professor cria } \\
\text { condições para o } \\
\text { aluno captar a essên- } \\
\text { cia do que está sendo } \\
\text { ensinado. O estudante } \\
\text { identifica princípios } \\
\text { e ideias, a essência do } \\
\text { assunto. }\end{array}$ & & & \\
\hline $\begin{array}{l}\text { INFORMAÇÃO } \\
\text { O professor apresenta } \\
\text { o conteúdo da aula. } \\
\text { O estudante recebe o } \\
\text { conteúdo. }\end{array}$ & & & & \\
\hline $\begin{array}{l}\text { Conhecimento dos fat } \\
\text { O que aconteceu? On }\end{array}$ & $\begin{array}{l}\text { TO } \\
\text { s e dados: } \\
\text { ? Como? Quando? }\end{array}$ & $\begin{array}{l}\text { SIGNIFICADO } \\
\text { Conhecer o signifi- } \\
\text { cado e implicações } \\
\text { do fato: Por que } \\
\text { aconteceu? Para que } \\
\text { aconteceu }\end{array}$ & $\begin{array}{l}\text { APLIC } \\
\text { Conhecer o fato e seu } \\
\text { cá-lo à vida em geral e } \\
\text { pessoal: E daí? O que e } \\
\text { isso? Onde eu entro ne } \\
\text { vou fazer? }\end{array}$ & $\begin{array}{l}\text { AÇÃO } \\
\text { significado, e apli- } \\
\text { à sua experiência } \\
\text { u tenho a ver com } \\
\text { essa história? O que }\end{array}$ \\
\hline
\end{tabular}


É importante observar que a ideia de Richard forma, deliberadamente, uma escada, conduzindo o professor e o estudante ao mais elevado estágio do processo ensino-aprendizagem: a ação e reação positivas diante daquilo que foi estudado.

A realidade do ensino da Bíblia nos mostra que, geralmente, o professor cumpre com os três primeiros passos da escada: Passa um conteúdo (Informação), explica para o estudante entender o assunto (Reconhecimento) e dá algumas atividades e tarefas (Expressão). Após concluir o terceiro passo, ele começa um novo conteúdo, perdendo, assim, a oportunidade de conduzir o aluno para um ensino mais completo e transformador, que seja a ponte entre o que a Bíblia disse há dois milênios, e o que isso implica no hoje, século XXI.

Ao preparar sua aula, portanto, o professor de Bíblia deve procurar ir num crescendo, atingindo cada um dos cinco passos, pois quanto mais alto o ponto atingido, maior o grau de aprendizagem significativa para o aluno. Ele pode ter como ponto de partida uma simples informação, mas deve necessariamente procurar uma tomada de decisão, que é o ponto alto no ensino da Bíblia.

\section{A operacionalização dos cinco passos do ensino criativo}

Cada um dos cinco passos precisa estar claramente planejado a fim de que o estudante seja deliberadamente conduzido pelo prazeroso caminho do ensino criativo e motivador. Isso implica num preparo consciente das aulas, visando levar o aluno para as alturas de um aprendizado transformador.

A seguir, veja algumas sugestões de como pôr em prática a metodologia do ensino criativo da Bíblia. 


\begin{tabular}{|c|c|}
\hline PASSOS & O QUE FAZER PARA ATINGI-LOS? \\
\hline INFORMAÇÃO & $\begin{array}{l}\text { - } \text { O aluno ouve a explicação da matéria pelo professor. } \\
\text { - O aluno lê o livro texto, cópia de um artigo, etc. } \\
\text { - } \quad \text { O aluno copia a informação. } \\
\text { - } \text { O aluno observa uma encenação. } \\
\text { - O aluno ouve um diálogo. } \\
\text { - O aluno assiste a um vídeo. } \\
\text { - O aluno ouve uma música. }\end{array}$ \\
\hline $\begin{array}{l}\text { RECONHECIMEN- } \\
\text { TO }\end{array}$ & $\begin{array}{l}\text { - } \quad \text { O aluno questiona o professor. } \\
\text { - O aluno dialoga com os colegas a respeito do assunto. } \\
\text { - } \quad \text { O aluno analisa uma história. } \\
\text { - } \quad \text { O aluno extrai ideias de um texto. } \\
\text { - O aluno interpreta a informação. } \\
\text { - O aluno descobre a essência de um capítulo da Bíblia. }\end{array}$ \\
\hline EXPRESSÃO & $\begin{array}{l}\text { - O aluno responde um questionário. } \\
\text { - O aluno organiza a informação em forma de resumo, esboço, mapa } \\
\text { - } \quad \text { O aluno sintetiza o assunto estudado num desenho. } \\
\text { - } \quad \text { O aluno faz uma dramatização. } \\
\text { - O aluno cria um recurso lúdico para fixar a informação recebida. } \\
\text { - O aluno faz um cartaz, maquete, etc. }\end{array}$ \\
\hline REFLEXÃO & $\begin{array}{l}\text { - O aluno relaciona a informação com uma situação atual, conhecida. } \\
\text { - O aluno lista semelhanças entra a informação bíblica e os fatos de } \\
\text { hoje. } \\
\text { - O aluno diz como seria tal cena bíblica caso acontecesse hoje. } \\
\text { - O aluno cria paráfrases com linguagem atual. } \\
\text { - O aluno recontar verbalmente a história bíblica, usando linguagem } \\
\text { atual. }\end{array}$ \\
\hline DECISÃO & $\begin{array}{l}\text { - } \quad \text { O aluno usa a informação para resolver um caso atual (estudo de caso) } \\
\text { - O aluno usar a informação e conhecimento para criar um problema e } \\
\text { resolvê-lo. } \\
\text { - O aluno se colocar no lugar do personagem analisado e diz como } \\
\text { reagiria numa situação semelhante. } \\
\text { - O aluno lista razões pelas quais a história bíblica é útil hoje. } \\
\text { - O aluno lista atitudes que possa tomar após estudar a lição. } \\
\text { O aluno decide o que fazer a curto prazo a fim de seguir o princípio } \\
\text { bíbrendido. }\end{array}$ \\
\hline
\end{tabular}




\section{Conclusão}

O ensino da Bíblia é um momento apropriado para o desenvolvimento de ações solidárias, pois nelas procura-se construir o diálogo e o respeito com e pelo outro. Desta maneira, é oportuno pensar numa abordagem adequada para efetivar o envolvimento dos estudantes em projetos solidários. A tarefa fica mais amena se a própria estrutura da aula colabora para tanto. Eis a razão pela qual, neste trabalho, procuramos pensar nessa possibilidade, sugerindo uma estrutura que permita transformar uma mera informação em ação concreta, de maneira que os alunos cresçam com a consciência da importância de saber e fazer algo em função do outro, pois aprender a viver juntos, considerando o outro como diferente, mas carente de ajuda, é educação no mais alto sentido.

É apropriado concluir este artigo com as sábias palavras de Lucien Coleman, as quais focalizam o papel do professor como decisivo neste intento:

Ensinar assemelha-se muito à prática de jardinagem. O jardineiro preocupa-se com o crescimento das plantas; o professor preocupa-se com o crescimento de pessoas. $\mathrm{O}$ jardineiro sabe estimular o potencial de crescimento que existe na semente; o professor sabe liberar o potencial de crescimento que existe no aluno. $\mathrm{O}$ jardineiro cuida bastante do ambiente que envolve suas plantas: ele propicia grande quantidade de luz solar, elevado teor de umidade e de nutrientes do solo. $\mathrm{O}$ professor propicia o clima que favorece o crescimento individual.

Mais importante ainda é que tanto jardineiros quanto professores são "cooperadores de Deus". Qualquer jardineiro que tenha sensibilidade espiritual dirá: "De modo que nem o que planta é alguma coisa, nem o que rega, mas Deus, que dá o crescimento". Pois ele sabe que o homem não pode fazer as plantas crescerem; ele só pode cooperar com os princípios de crescimento que o Criador estabeleceu na ordem natural. De maneira semelhante, o professor Cristão que tenha sensibilidade espiritual reconhecerá com humildade e de bom grado sua dependência de Deus para ensinar. ${ }^{18}$

\footnotetext{
${ }^{18}$ Lucien E. Coleman Júnio, Como ensinar a Bíblia (Rio de Janeiro: JUERP, 1995), 20.
} 